\title{
A new design approach to the use of composite materials for heavy transport vehicles
}

\section{Tommaso Ingrassia, * Gianluca Alaimo, Francesco Cappello, Antonio Mancuso and Vincenzo Nigrelli}

\author{
Department of Mechanics, \\ University of Palermo, \\ Viale delle Scienze, \\ Palermo 90128, Italy \\ E-mail: ingrassia@dima.unipa.it \\ E-mail: gianlucaalaimo@hotmail.com \\ E-mail: cappello@dima.unipa.it \\ E-mail:mancuso@dima.unipa.it \\ E-mail: nigrelli@dima.unipa.it \\ ${ }^{\star}$ Corresponding author
}

\begin{abstract}
In order to keep or to reach a high level of competitiveness and performance of a product, it is necessary to explore all the possible solutions that allow the best compromise between costs and project requirements. By this point of view the study of alternative designs and/or materials to use, is an important aspect that can identify a new concept or way of thinking about a product. This paper presents how to make use of composite materials in the field of heavy vehicles transportation. A new semitrailer in composite material has been designed, using a methodical redesign approach and an optimisation process. The main innovation in this project is, besides the use of the Glass Fibre Reinforced Plastics (GFRPs), also a new topology of the vehicle frame; the designed semitrailer, in fact, has a monocoque structure.
\end{abstract}

Keywords: redesign process; semitrailer; structural frame; composite material.

Reference to this paper should be made as follows: Ingrassia, T., Alaimo, G., Cappello, F., Mancuso, A. and Nigrelli, V. (2007) 'A new design approach to the use of composite materials for heavy transport vehicles', Int. J. Vehicle Design, Vol. 44, Nos. 3/4, pp.311-325.

Biographical notes: Tommaso Ingrassia is a $\mathrm{PhD}$ student in Mechanical Engineering at the Department of Mechanics of the University of Palermo (Italy). He received his degree in Mechanical Engineering in 2003. He was a Visiting Researcher at the Graphitech Foundation. He is responsible of the 'Virtual Reality Lab' of the University of Palermo. His main research activities are about redesign methodologies, virtual reality in mechanical design, composite material, multiobjective and topological optimisation.

Gianluca Alaimo is a student in Mechanical Engineering in the Department of Mechanics of the University of Palermo in Italy. His main skills are about: FEM analyses, composite material, multi-objective optimisation.

Francesco Cappello is Full-time Professor at the Department of Mechanics of the Palermo University, of which he has been the Director. He has performed many research activities in collaboration with Michigan State, Belgrade and other Italian Universities, Graphitech Foundation, FIAT, ELASIS, 
FIAT-AVIO; he is author of over 100 scientific papers. He is responsible to: 'Laboratory for virtual reality' project; contract of an abroad Italian researcher, returned to Italy for research on 'New computational methods to study mechanical properties of nanocomposites materials'. Palermo RU of the project 'From Systematic Innovation to Integrated Product Development'.

Antonio Mancuso has been Assistant Professor since 1996 at the Department of Mechanics of the Faculty of Engineering of Palermo University, Italy. $\mathrm{He}$ received his degree in Aeronautical Engineering in 1991 and his $\mathrm{PhD}$ in Mechanical Engineering in 1995 with a dissertation on filament wound pressure vessels for aero-spatial applications. His research interests are structural and shape optimisations, mainly in the sailing yacht field. He also works in virtual reality applications for an Italian research project.

Vincenzo Nigrelli is a Professor of Machine Drawing at the Department of 'Meccanica', University of Palermo. He is author of 80 papers and his present activity is reverse engineering, topological and shape optimisation, image processing, and non-destructive evaluation and he is active in national research programs (PRIN), assignor of research funds, team leader of EU project under the 6th Framework Research Programme. He is also the Official Professor of Fundamentals of Industrial Design and temporary Professor of: Computer Aided Draft and Applications in Electrical Engineering Field; Mechanics of Materials. Socrates-Erasmus coordinator of his department and of the Mechanical Engineering Degree Course of Palermo.

\section{Introduction}

Road haulage is by far the most important form of transport for goods and is expected to grow by $25 \%$ over the next 15 years. This growth is in conflict with the environment because:

- $30 \%$ of the total energy consumption is due to the transportation field

- the road transportation causes, by itself, $75 \%$ of total carbon dioxide $\left(\mathrm{CO}_{2}\right)$ emissions

- road transportation gives a big contribution to the greenhouse effect'

- the damage of roads and bridges caused by heavy vehicle transportation is remarkable.

Besides the above-mentioned important factors workers in the commercial vehicle field also particularly feel the need for making the most of the capability of transport, increasing the maximum loading capacity (payload) and of reducing the consumption of fuel and wear of the tyres.

The focal point of this problem is represented by the vehicle frame weight; it is the primary determinant of fuel economy: $75 \%$ of a vehicle's energy consumption directly relates to factors associated with its weight (Budd Report, 2001). Reducing fuel consumption would ameliorate all the matters related to the bad emissions, air pollution, etc. Besides it is simple to understand that a lighter vehicle weighs less upon roads and bridges and has a lower tyre wear. Moreover because the regulations prescribe a total 
weight depending on the class of the vehicle, when the total weight is equal to the limit of the class, weight reduction of the semitrailer also allows the loading capability to be increased. This represents an advantage when vehicles are loaded, because the impact of costs, emissions and wear on unit payload decreases.

In the work here presented the problem of heavy vehicle weight has been studied in depth by a redesign process (Hyman, 1998; Otto and Wood, 2001).

It is obvious that such a redesign process must be developed in a methodical way in order to minimise the possibility of non-optimal solutions due to bad choices. For the above reasons, a good redesign process is made using a methodical and structured approach (Cappello et al., 2005; Otto and Wood, 2001) that would drive the project staff from a starting point (As-Is-State), representing the state of the art of product, to a final point (To-Be-State) (Vernadat, 1996), representing the optimal product solution, a target. To carry out, in a structured way, a redesign process one needs to know the different available techniques and tools (Cross, 1999; Eppinger and Ulrich, 2000) that allow to choices to be made in a more efficient and objective way.

Following these guidelines, a methodical redesign process of a semitrailer has been carried out, with the aim of reducing its weight. To reach this objective two main solutions are possible: using a lighter material and/or changing the topology of the semitrailer frame.

The first solution is suggested by the trend of these last years, in fact, above all in aerospatial field (Baker and Hoskin, 1986), but not only (e.g. naval constructions) (Shenoi and Wellicome, 1993), the use of lighter materials, such as aluminium alloys or composites, has been tested for different purposes (Atkinson, 1997; Ballinger, 1995; Larrodé et al., 1995). Also solutions using sandwich constructions have been used to reduce the weight of urban buses (Crocker et al., 2000; Gauthier et al., 1999; Schellens and Peijs, 1999).

In the field of heavy transportation, the use of composite materials is also being extended to the production of trailers (Larrodé et al., 1998). Some examples of semitrailer with a mixed structure in composite material and steel have been studied and tested. One example is the HYCOPROD (Dappolonia, http://www.dappolonia.it/hycoprod/) refrigerated semi-trailer manufactured by Box Modul and APC Composit in Sweden. The trailer is manufactured in fibreglass/foam sandwich panels using vacuum infusion. These materials provide a remarkable weight saving (or increased payload) compared to a traditional design. Furthermore, a prototype has successfully completed more than $250,000 \mathrm{~km}$ on a test track. Other examples are the Composittralier, Sicomp and Martin Marietta semitrailer, which is yet mass-produced and is constituted by a frame in steel and a floor in composite materials (sandwich panels) (Martin Marietta, http://www.martinmarietta.com/Products/trailers.asp).

Nevertheless, entirely composite structures for heavy vehicles, like semitrailers, are not yet mass-produced by industry, but some research plans have been worked out.

In addition to the lightening of a structure, using the composite material offers many other benefits. The durability of composites provides higher dent and corrosion resistance than the traditional metals. Fibre-reinforced polymer materials are resistant to corrosion and deterioration from chemicals, acids, road salts and weathering. They do not rust and are not susceptible to oxidation. Because several plastic parts can be moulded together in one operation, manufacturers can consolidate composite parts for easy assembly. A reduction in noise, vibration and hardness also makes composites a 
preferable alternative to steel. Composites are non-flammable, self-extinguishing and resistant to fatigue (Bertholet and Cole, 1998).

Small repairs can be easily accomplished using a fibreglass repair kit. For larger repairs, components can be replaced quickly without causing any loss of strength.

As regards the development of a new semitrailer topology, the main idea is to replace the classical structure, constituted by a heavy chassis in steel and a bodywork, by a structural bodywork, lighter and characterised also by better torsional and longitudinal stiffness. This evolution started in the decade 1920-1930 with cars and has influenced the design of buses even more (Faraggiana, 1990), through the development of monocoque structures.

Coupling the change of topology of the vehicle and the employment of composite material represents the best solution in order to reduce the vehicle mass (Cappello et al., 2003).

In this paper, a new semitrailer is presented; it is characterised, besides by the frame in composite material Glass Fibre Reinforced Plastic (GFRP), also by a new topology; it has, in fact, a monocoque structure, a structural floor.

Dimensioning of the structure has been performed by means of an optimisation process using a Finite Element Method (FEM) software.

\section{Design approach}

In order to identify the best solution for lightening the standard semitrailer, a methodical, structured design approach was made use of. Design problems can be more or less complex and big, but they are all parts of a basic scheme (Cross, 1999) in which the three most important points are: one or more goals (to be state), one or more constraints (or specifications) and one or more criteria to recognise the best solution.

Generally three different phases (Otto and Wood, 2001) form the design process: the reverse engineering, the development of the design process and the implementation of the design process (Cappello et al., 2005). The first stage (reverse engineering) needs to state the objectives and the specifications (Otto and Wood, 2001), the second one is useful to create several different solutions and choose the best one, in the last phase the selected solution is studied in depth until to define its behaviour and performances. All these principles have been adopted to design a new, lighter semitrailer. During this design process the standard semitrailer was studied to define the specifications of the new product, afterwards many alternative solutions have been created and finally amongst these, the best one has been chosen and studied. All this process has led to design a new semitrailer with a structural floor in composite material.

\subsection{Identifying the semitrailer specifications}

It is quite simple to state that the goal of this design process is to create a cost effective and multifunctional lighter semitrailer chassis. This target can be achieved by using affordable materials, like glass fibre composites, making use of low cost production processes and the modern design tools like Computer Aided Design (CAD) and FEM software. 
To identify the requirements that the new designed semitrailer must have, a careful study of a standard semitrailer (Figure 1) was carried out. Two longitudinal beams and many crossbars in steel form the chassis of the studied semitrailer, to which the suspensions are directly connected; the main characteristics of this kind of vehicle are:

- maximum length: $12,500 \mathrm{~mm}$

- maximum width: $2500 \mathrm{~mm}$

- front overhang: $1100 \mathrm{~mm}$

- rear overhang: $2145 \mathrm{~mm}$

- wheel track: $2100 \mathrm{~mm}$

- height: $1450 \mathrm{~mm}$

- $\quad$ tare: $3900 \mathrm{~kg}$

- chassis mass: $2778 \mathrm{~kg}$

- payload: $32,100 \mathrm{~kg}$

- maximum weight: $36,000 \mathrm{~kg}$

- $\quad$ reaction at fifth-wheel: $11,707 \mathrm{~kg}$

- reaction at 1 st axle: $8096 \mathrm{~kg}$

- reaction at 2 nd axle: $8103 \mathrm{~kg}$ and

- reaction at 3rd axle: $8094 \mathrm{~kg}$.

Figure 1 Standard semitrailer frame in steel

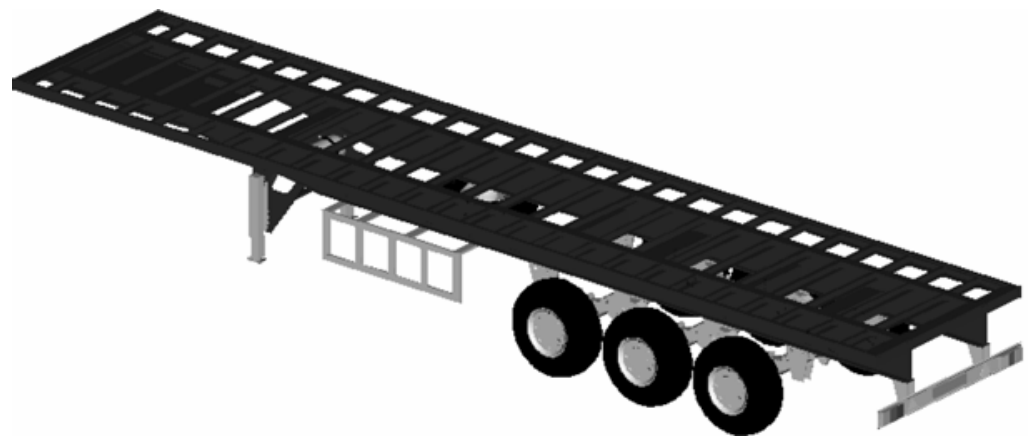

This semitrailer has been studied by numerical analysis making use of the FEM codes. For the meshing of the steel frame model, single-layer eight-node shell elements have been used; shell, beam and link elements have been used to mesh, in a schematic way, the suspensions (Figure 2) that consist of leaf springs and connecting rods (for the balancing of the reactions at the axles).

Four different load conditions have been considered: rectilinear motion; isolated semitrailer (stop); motion in curve (Genta, 1998); difference of level between the wheels of the two sides (torsional loading). The total load was constituted by the semitrailer weight and the payload; the first one was calculated by FEM code assigning mass density and gravity acceleration; as prescribed by regulations, except for the torsional loading case, the payload has been considered uniformly distributed on the floor surface; for the condition of motion in curve the maximum possible centrifugal force has been applied. 
Figure 2 FEM schematisation of the suspensions

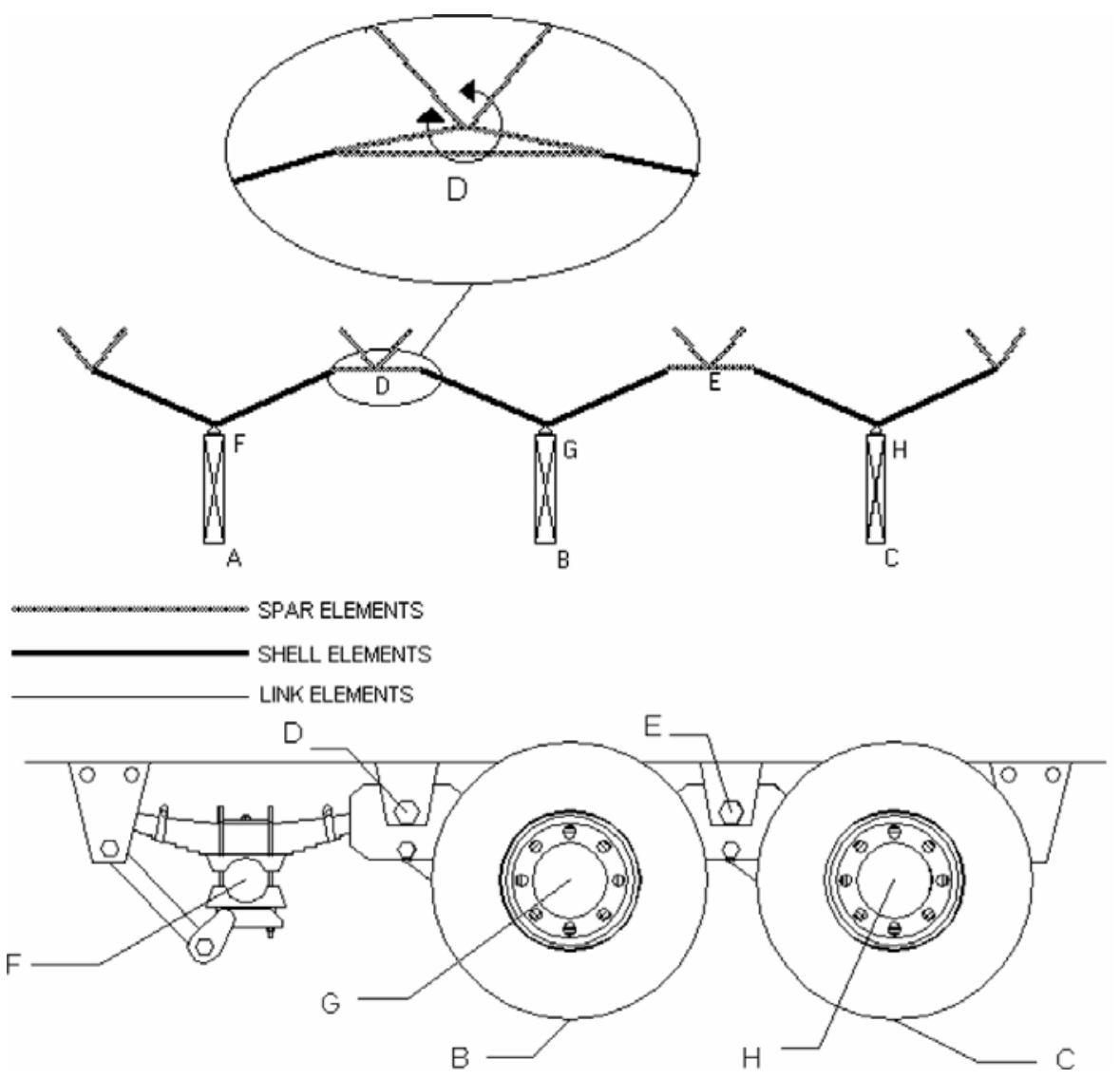

The minimum values of the safety factor are: 2 for rectilinear motion and uniform speed and 1.5 in case of semitrailer unhooked by tractor.

Last two configurations are not considered by the regulations so it has been considered as opportune to impose a safety factor not lower than 1.25. For the last case an index of torsional stiffness has been defined as $K_{t}=\Delta Z / L=\left(U z_{2}-U z_{1}\right) / L$ (Figure 3). FEM analyses have allowed to calculate the following data characterising the behaviour of the standard semitrailer in steel:

- $\quad$ safety factor for rectilinear motion: 2.24

- maximum vertical deflection in rectilinear motion: $95.5 \mathrm{~mm}$

- $\quad$ safety factor for stop: 3.5

- $\quad$ safety factor for motion in curve: 1.26

- $\quad$ safety factor for difference of level between the wheels: 1.54 and

- $\quad$ index of torsional stiffness: 92. 
Figure 3 Variables used for determining $K_{t}$ in the standard semitrailer in steel

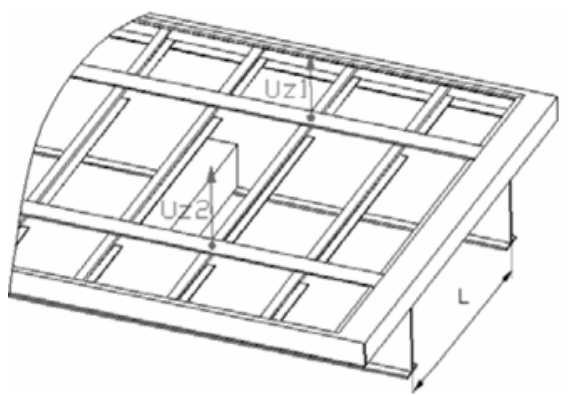

Figure 4 shows the distribution of the equivalent stress, near the fifth wheel, in the FEM model of the semitrailer in steel, in case of rectilinear motion.

Figure 4 FEM model of the standard semitrailer in steel: distribution of the equivalent stress near the fifth-wheel

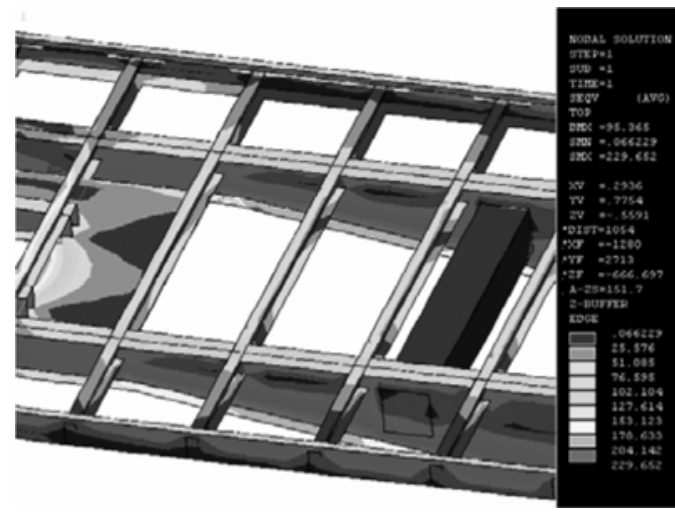

Having defined the characteristics and the behaviour of the semitrailer in steel, it is possible to establish the specifications of the newly designed semitrailer. In all load conditions the new lighter semitrailer must match or exceed the structural properties of a standard semitrailer in steel, like flexural rigidity and torsional stiffness. Moreover the chassis in composite material must have the same size as the steel one, allowing also to accommodate all the parts and the necessary accessories.

\subsection{Selection and study of the solution}

After defining the main goal and the requested specifications, many different possible solutions have been proposed:

- reduction of the thicknesses of the sections of the structural elements

- modification of the geometry of the structural elements

- $\quad$ use of alternative materials (like composite material and aluminium alloy) and

- change of the topology of the frame. 
The study of the different proposed intervention solutions and their possible synergistic combinations has led to produce many extra possible solutions, of which the most interesting, after a preliminary evaluation using the concept screening technique (Eppinger and Ulrich, 2000), have been the following:

- building the semitrailer in composite material (or aluminium)

- building the semitrailer in composite material (or aluminium) modifying also its topology and

- building the semitrailer in steel with reduction of the thicknesses.

The proposed change of the topology refers to the use of a monocoque structure (a structural floor) so giving up the standard structure composed by frame and floor.

To select in objective way the best solution, the concept scoring technique has been used (Eppinger and Ulrich, 2000). The matrix of decisions is presented in Table 1, and the principal evaluation criteria that have been considered are:

- entity of reduction of the mass

- resistance of the structure

- stiffness of the structure and

- easiness and realisation costs.

By this matrix it is possible to state that the best solution is a semitrailer with a structural floor made in composite material.

Table 1 Matrix of decisions in the concept scoring

\begin{tabular}{lccccccc}
\hline & & \multicolumn{2}{c}{$\begin{array}{c}\text { Structural floor in } \\
\text { GRFP }\end{array}$} & $\begin{array}{c}\text { Structural floor in } \\
\text { aluminium }\end{array}$ & $\begin{array}{c}\text { Reduction of the } \\
\text { thickness }\end{array}$ \\
\cline { 2 - 8 } & Weight & Vote & $\begin{array}{c}\text { Partial } \\
\text { score }\end{array}$ & Vote & $\begin{array}{l}\text { Partial } \\
\text { score }\end{array}$ & Vote & $\begin{array}{l}\text { Partial } \\
\text { score }\end{array}$ \\
\hline $\begin{array}{l}\text { Reduction of the } \\
\text { mass }\end{array}$ & 10 & 8 & 80 & 7 & 70 & 3 & 30 \\
$\begin{array}{l}\text { Safety conditions } \\
\text { Displacements }\end{array}$ & 10 & 10 & 100 & 10 & 100 & 10 & 100 \\
$\begin{array}{l}\text { Price } \\
\text { Easiness to carry } \\
\text { out }\end{array}$ & 7 & 8 & 56 & 8 & 56 & 8 & 56 \\
$\begin{array}{l}\text { Easiness to } \\
\text { assemble }\end{array}$ & 8 & 6 & 42 & 7 & 49 & 9 & 63 \\
Total score & 8 & 64 & 3 & 24 & 8 & 64 \\
\hline
\end{tabular}

The new structural floor consists of one perimetrical bodywork (floor) seat of the anchorages of the various conventional types of up-structures (Figure 5). As regards its production, it was thought, because of its tubular shape, to use the filament winding technology (Kelly and Zweben, 2000) to produce the structural floor in composite material. 
Figure 5 Structural floor in composite material

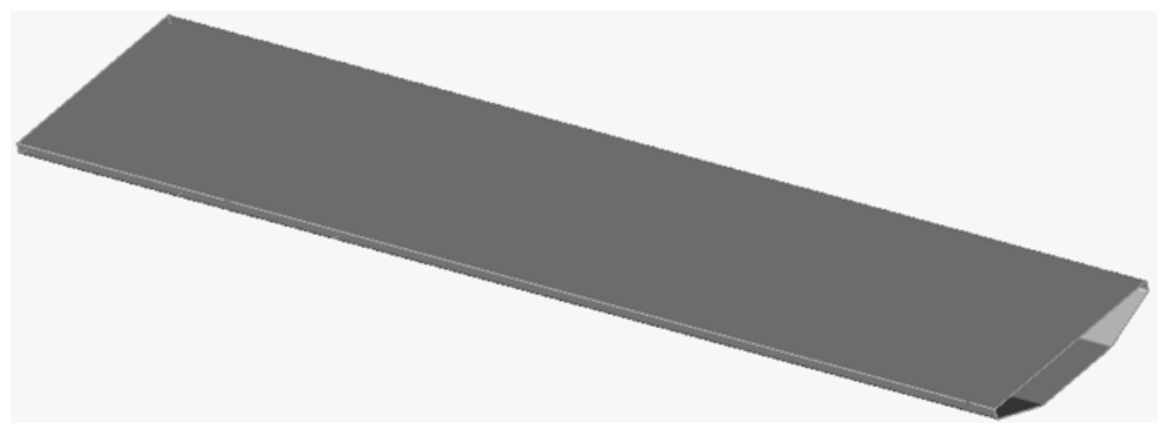

In order to simplify the total structure and to increase its stiffness the presence of a little chassis in steel (Figure 6) to which connecting the monocoque has been prescribed. This chassis is also used to join the suspensions to the monocoque in composite. The sum of the floor and chassis heights is equal to the height of the standard semitrailer frame.

Figure 6 Chassis in steel located under the rear part of the monocoque for the joining of the suspensions

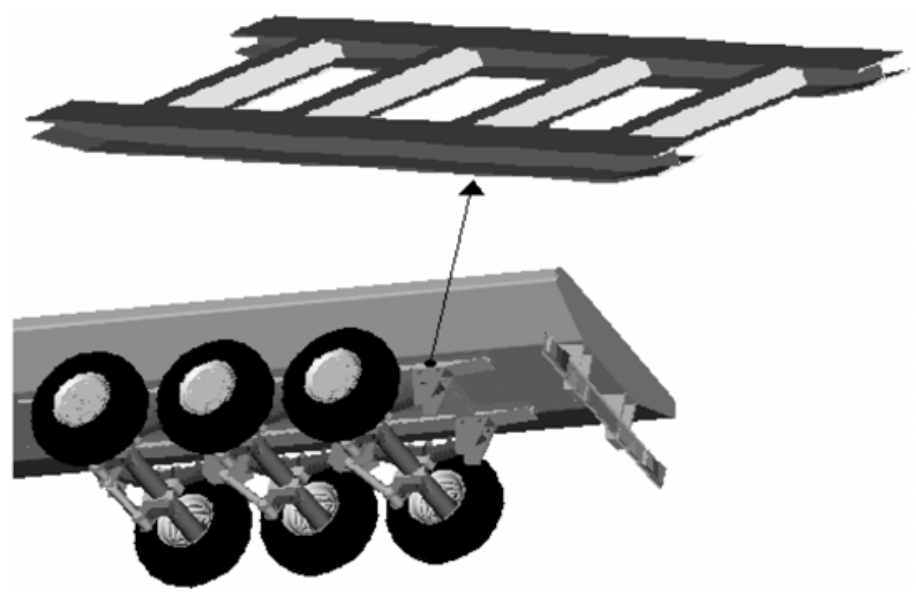

Anyway this chassis is not enough to maintain within acceptable limits lateral and vertical displacements of the floor. For this reason various configurations were studied for the stiffening of monocoque, by means of the insertion inside perimetrical structure of reinforcement elements (Figure 7).

Figure 7 Possible solutions for the internal reinforcement of the structural floor

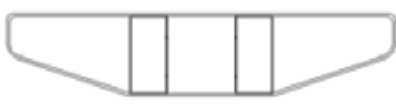

(a)

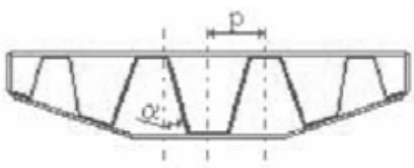

(b) 
The first solution (Figure 7(a)) makes use of two longitudinal beams with a rectangular section, and the second (Figure 7(b)) is made up of a more distributed reinforcement, quite similar to honeycomb structures. Both solutions have been studied to evaluate the best one.

In previous works (Cappello et al., 2003, 2005) results related to solution (a) were presented, here new data as regards solution (b) are talked about.

The composite material is a GFRP having a volume fraction of the fibres of $45 \%$ and the characteristics shown in Table 2.

Table 2 Characteristics of the composite material

\begin{tabular}{lllllll}
\hline$E_{x}(M P a)$ & $E_{y}(M P a)$ & $V_{x y}$ & $V_{x z}$ & $G_{x y}[M P a]$ & $V_{f}$ & $\rho\left(g / \mathrm{cm}^{3}\right)$ \\
44,767 & 13,569 & 0.28 & 0.09 & 4269 & $45 \%$ & 1.8 \\
$\sigma_{x, t}(M P a)$ & $\sigma_{x, c}(M P a)$ & $\sigma_{y, t}(M P a)$ & $\sigma_{y, c}(M P a)$ & $\tau_{x y}(M P a)$ & & $\tau_{y z}(M P a)$ \\
1280 & -690 & 49 & -158 & 69 & & 69 \\
\hline
\end{tabular}

\section{Optimisation problem}

In order to obtain the best performances of the new designed semitrailer in composite material, an optimisation process has been carried out; the objective of this process is minimising the mass $M$ of the semitrailer frame, constituted by the monocoque in GFRP and the little chassis in steel.

This procedure was performed by the FEM software ANSYS making use of the response surface optimisation algorithm (ANSYS, 2004; Montgomery, 1996).

Based on previous studies (Cappello et al., 2003, 2004) it has been established to use both for the monocoque and for the internal reinforcement in composite material two unidirectional layers with $0^{\circ}$ and $90^{\circ}$ orientations.

The optimisation problem can be formulated as follows:

$$
\begin{aligned}
& \text { Minimise } M\left(t_{1 \mathrm{~m}}, t_{2 \mathrm{~m}}, t_{\mathrm{b}}, t_{\mathrm{c}}, t_{1 \mathrm{r}}, t_{2}, \alpha, p\right) \\
& \text { s.t. } \\
& \eta_{1} \leq 2 \\
& \eta_{2} \leq 1.5 \\
& \eta_{3} \leq 1.25 \\
& \eta_{4} \leq 1.25 \\
& K_{t} \leq 92 \\
& D_{\max } \leq 95.5 \mathrm{~mm}
\end{aligned}
$$

where $t_{1 \mathrm{~m}}$ and $t_{2 \mathrm{~m}}$ are the thicknesses of the $0^{\circ}$ and $90^{\circ}$ layers of the monocoque; $t_{\mathrm{b}}$ and $t_{\mathrm{c}}$ are the thicknesses of the beams and the crossbars of the little chassis in steel; $t_{1 \mathrm{r}}$ and $t_{2 \mathrm{r}}$ are the thicknesses of the $0^{\circ}$ and $90^{\circ}$ layers of the internal reinforcement faces of the monocoque; $\alpha$ and $p$ are the slope and the pitch of the internal reinforcement faces (Figure $7(\mathrm{~b})) ; \eta_{1}, \eta_{2}, \eta_{3}$ and $\eta_{4}$ are, respectively, the safety factors for rectilinear motion, 
stop, torsional load and curvilinear motion; $K_{\mathrm{t}}$ is the index of torsional stiffness and $D_{\max }$ is the maximum vertical deflection in rectilinear motion.

To calculate the safety factors in all loading conditions the Tsai-Wu criterion has been used, assuming as failure load the First Ply Failure (FPF) one (Christensen, 1980).

The limits of the index of torsional stiffness $K_{\mathrm{t}}$ and the maximum vertical deflection in rectilinear motion $D_{\max }$ are represented by the values calculated for the standard semitrailer in steel, because it requires a level of control and stability for the semitrailer in GFRP not lower than the standard one.

Much attention was paid in carrying out the parametric FEM model (Figure 8); in fact, because of changing the slope and/or the pitch of the reinforcement faces, also the model geometry and consequently the mesh change, so they need to be updated at every cycle inside the optimisation procedure. For the meshing of the model, multilayered eight-noded shell elements have been used for the perimetrical bodywork in composite material, and single-layer eight-noded shell elements have been used for the little chassis in steel; for the suspensions, the same model adopted for the study of the standard semitrailer has been used (Figure 2).

Figure 8 FEM model of the reinforced monocoque in GFRP

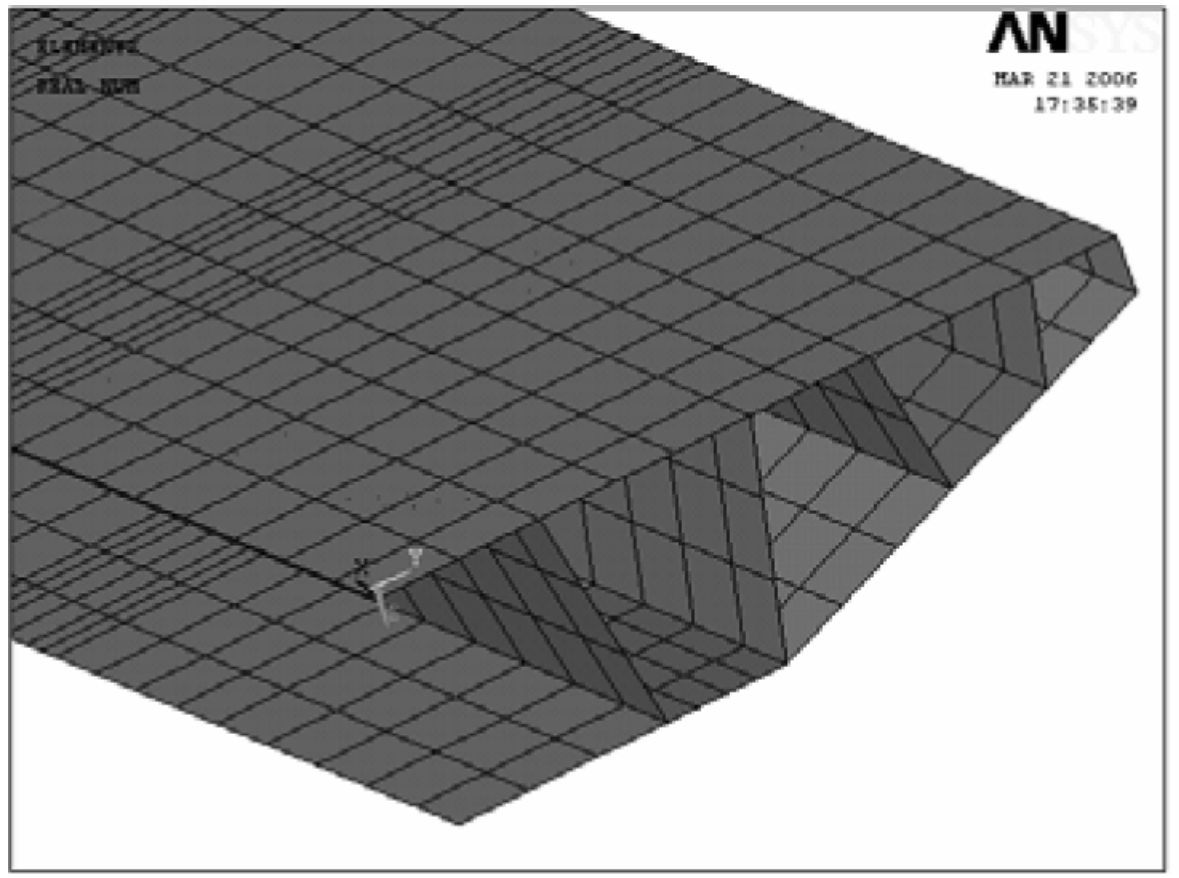

The limits of the variables and the values calculated at the end of the optimisation process are given in Table 3; the values of the constraints calculated for the new structural floor in GFRP are compared with those (in brackets) of the semitrailer in steel. 
Table 3 Variables in the optimisation problem

\begin{tabular}{|c|c|c|c|c|c|}
\hline Kind of variable & Symbol & Name & Lower limit & Upper limit & $\begin{array}{l}\text { Optimum } \\
\text { value }\end{array}$ \\
\hline $\begin{array}{l}\text { Objective } \\
\text { function }\end{array}$ & $M$ & $\begin{array}{l}\text { Mass of the } \\
\text { semitrailer frame }\end{array}$ & - & - & $1868 \mathrm{~kg}$ \\
\hline Design variable & $t_{1 \mathrm{~m}}$ & $\begin{array}{l}\text { Thickness of the } 0^{\circ} \\
\text { floor layer }\end{array}$ & $1.5 \mathrm{~mm}$ & $10 \mathrm{~mm}$ & $7.5 \mathrm{~mm}$ \\
\hline Design variable & $t_{2 \mathrm{~m}}$ & $\begin{array}{l}\text { Thickness of the } 90^{\circ} \\
\text { floor layer }\end{array}$ & $1.5 \mathrm{~mm}$ & $10 \mathrm{~mm}$ & $3.3 \mathrm{~mm}$ \\
\hline Design variable & $t_{\mathrm{lr}}$ & $\begin{array}{l}\text { Thickness of the } 0^{\circ} \\
\text { internal reinforcement } \\
\text { layer }\end{array}$ & $1.5 \mathrm{~mm}$ & $10 \mathrm{~mm}$ & $1.9 \mathrm{~mm}$ \\
\hline Design variable & $t_{2 \mathrm{r}}$ & $\begin{array}{l}\text { Thickness of the } 90^{\circ} \\
\text { internal reinforcement } \\
\text { layer }\end{array}$ & $1.5 \mathrm{~mm}$ & $10 \mathrm{~mm}$ & $3.4 \mathrm{~mm}$ \\
\hline Design variable & $\alpha$ & $\begin{array}{l}\text { Slope of the } \\
\text { reinforcement faces }\end{array}$ & $20^{\circ}$ & $45^{\circ}$ & $40^{\circ}$ \\
\hline Design variable & $p$ & $\begin{array}{l}\text { Pitch of the } \\
\text { reinforcement }\end{array}$ & $150 \mathrm{~mm}$ & $250 \mathrm{~mm}$ & $230 \mathrm{~mm}$ \\
\hline Design variable & $t_{\mathrm{b}}$ & $\begin{array}{l}\text { Thickness of the } \\
\text { longitudinal beams of } \\
\text { the little chassis in } \\
\text { steel }\end{array}$ & $4 \mathrm{~mm}$ & $10 \mathrm{~mm}$ & $5.8 \mathrm{~mm}$ \\
\hline Design variable & $t_{\mathrm{c}}$ & $\begin{array}{l}\text { Thickness of the } \\
\text { crossbars of the little } \\
\text { chassis in steel }\end{array}$ & $4 \mathrm{~mm}$ & $10 \mathrm{~mm}$ & $4.5 \mathrm{~mm}$ \\
\hline Constraint & $D_{\text {max }}$ & $\begin{array}{l}\text { Maximum vertical } \\
\text { deflection }\end{array}$ & - & $95.5 \mathrm{~mm}$ & $\begin{array}{l}92 \mathrm{~mm} \\
(95.5 \mathrm{~mm})\end{array}$ \\
\hline Constraint & $K_{\mathrm{t}}$ & $\begin{array}{l}\text { Torsional stiffness } \\
\text { index }\end{array}$ & - & $92.0 \mathrm{~mm}$ & $87(92 \mathrm{~mm})$ \\
\hline Constraint & $\eta_{1}$ & $\begin{array}{l}\text { Safety factor in } \\
\text { rectilinear motion }\end{array}$ & 2 & - & $2.1(2.24)$ \\
\hline Constraint & $\eta_{2}$ & Safety factor in stop & 1.5 & - & $1.7(3.5)$ \\
\hline Constraint & $\eta_{3}$ & $\begin{array}{l}\text { Safety factor for } \\
\text { torsional loading }\end{array}$ & 1.25 & - & $2.1(1.54)$ \\
\hline Constraint & $\eta_{4}$ & $\begin{array}{l}\text { Safety factor in } \\
\text { curvilinear motion }\end{array}$ & 1.25 & - & $1.25(1.26)$ \\
\hline
\end{tabular}

Results show that the structure in composite material (including the little chassis in steel) is lighter than the standard one by about $30 \%$ and it is slightly stiffer both for bending and torsion.

\section{Joining parts of the semitrailer}

The study concerning the joints among the various members of the semitrailer has held a very focal and very important role for the whole development of the project. The traditionally used solutions (e.g. welding) for steel semitrailers, are not applicable to the 
monocoque structure in composite material and the problem is obviously not negligible for the zones, like the kingpin and the suspension supports, where the exchanged forces are very high. For the structural floor in composite material hybrid joints (Lees, 1984; Matthews, 1987) have been chosen. For the different joints the use of some threaded bars passing through the floor and a structural adhesive in the interfaces was tested. The threaded bars (Figures 9 and 10) serve both for the joining of the internal renforcement to the perimetrical structure in composite material and for the joining of the other accessories. In particular the threaded bars employed to join the supports of the protection systems, the air cylinder and the spare tyre, have two different diameters; the part with smaller section is used for the above-mentioned joints according to the scheme visible in Figure 9. In case of the steel plate supporting the kingpin of the tractor, because it is impossible to admit projections in the interface, to avoid interference, the threaded bars are welded to the plate itself and the clamping is made from the upper part of the floor. All remaining small accessories can be joined to the chassis by rivets.

Figure 9 Model of the supports joint

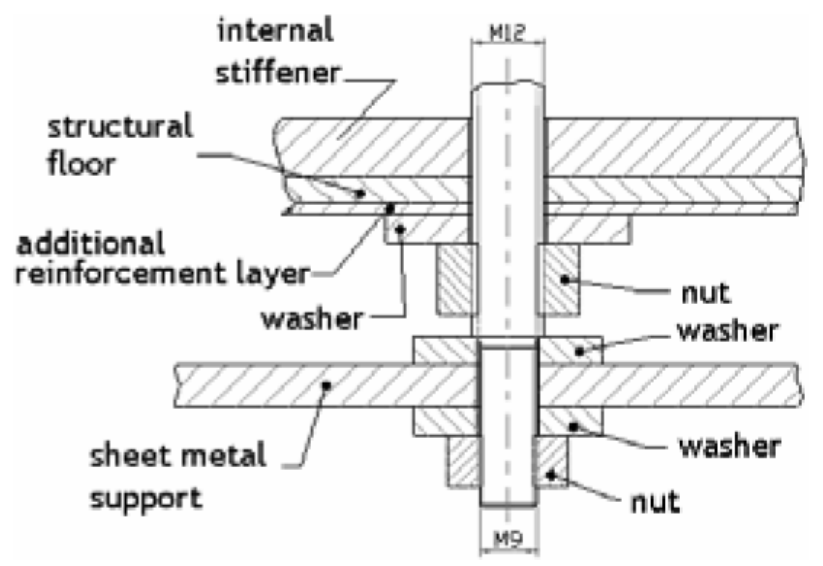

Figure 10 View of the rear of the semitrailer in composite material with the internal reinforcement faces and the threaded bars

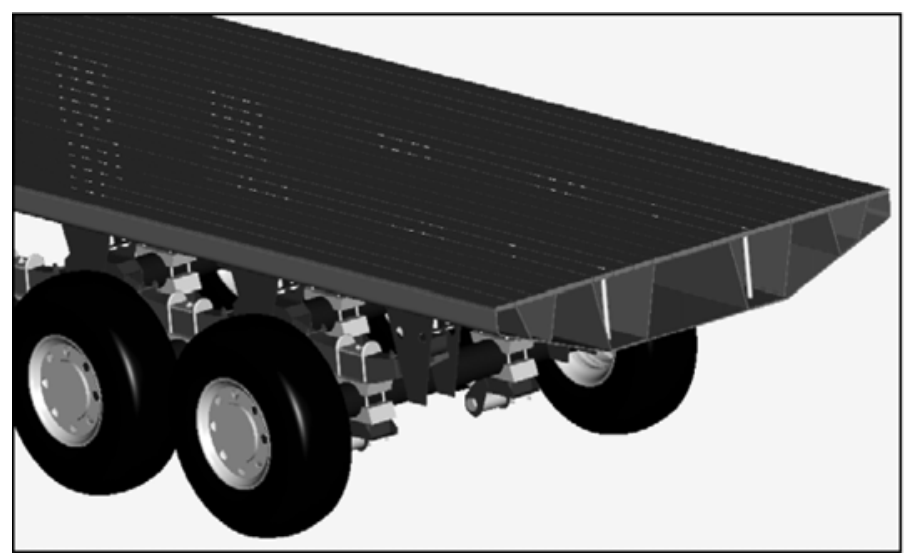


When using mechanical joints it is necessary to drill the structure in composite material. Unfortunately the presence of holes and cut-outs creates stress concentrations, and the lack of plasticity of composites limits stress redistribution; moreover, composites can have a tendency to delaminate as a result of localised drilling. For these reasons the area around the holes has been studied more in depth by a submodelling analysis (ANSYS, 2004). At the end of this test, it was decided to use locally additional reinforcement layers (Figure 9) to limit, under safe values, the stress peaks.

\section{Conclusions and future works}

In this paper presented a study related to a new semitrailer with a structural floor in glass fibre reinforced plastic. The use of the composite material and the change of topology have allowed to obtain a frame weight of only $1868 \mathrm{~kg}$ (about $30 \%$ less than the semitrailer in steel), with the capability of a $32,700 \mathrm{~kg}$ payload.

The new semitrailer in composite (Figure 10), furthermore, has better structural properties (higher bending and torsional stiffness) than the standard one in steel.

It is a multifunctional chassis so it can be adjusted depending on the specific application: it can be used as flat bed, curtain sided or boxed trailer (like fridge vans).

The adopted monocoque structure, besides giving good structural properties, allows a more continuous stress transfer from the loading floor to the frame.

Other future works will examine buckling and modal analyses, and crash and fatigue tests to validate the obtained results. At the end of these numerical verifications a prototype can be tested.

\section{References}

ANSYS Inc. (2004) Theory Reference.

Atkinson, R. (1997) Innovative Uses for Sandwich Constructions, Reinforced Plastics, February.

Baker, A.A. and Hoskin, B.C. (1986) Composite Materials for Aircraft Structures, New York: AIAA.

Ballinger, C.A. (1995) Getting Composites into Construction, Reinforced Plastics, April.

Bertholet, J.M. and Cole, J.M. (1998) 'Composite materials: mechanical behavior and structural analysis - technology', December, Springer Edition.

Budd Report (2001) Available at: http://statusreports-atp.nist.gov/reports/94-02-0040.htm.

Cappello, F., Ingrassia, T., Mancuso, A. and Nigrelli, V. (2003) 'Approccio Metodico alla Riprogettazione di un Semirimorchio', Proceedings of XIII ADM- XV INGEGRAF, Napoli.

Cappello, F., Ingrassia, T., Mancuso, A. and Nigrelli, V. (2005) 'Methodical redesign of a semitrailer', Computer Aided Optimum Design in Engineering, WIT Press.

Cappello, F., Ingrassia, T., Mancuso, A. and Nigrelli, V.(2004) 'L'implementazione del processo di redesign', National Conference XIV ADM - XXIII AIAS, Bari, September.

Christensen, R. (1980) Mechanics of Composite Materials, Canada: J. Wiley \& Sons.

Crocker, J., DesRochers, C. and Zgela, M. (2000) Intercity Bus Weight Reduction Program, Halifax Nova Scotia, Gennaio.

Cross, N. (1999) Engineering Design Methods, Chichester: J. Wiley \& Sons.

Eppinger, S.D. and Ulrich, K.T. (2000) Product Design and Development, USA: McGraw-Hill.

Faraggiana, G. (1990) Note sul Calcolo delle Carrozzerie Portanti negli Autobus, ATA, Rendiconti della VI Riunione Annuale. 
Gauthier, A., Gauvin, R. and Labonté, S. (1999) Programme de Reduction du Poids des Autobus Urbains: Phase I, Québec, Marzo.

Genta, G. (1998) Meccanica dell'Autoveicolo, Torino: Levrotto \& Bella.

Hyman, B. (1998) Fundamentals of Engineering Design, New Jersey: Prentice-Hall.

Kelly, A. and Zweben, C. (2000) Comprehensive Composite Materials, Vol. 6, Cambridge: Cambridge University Press.

Larrodé, E., Miravete, A. and Castejón, L. (1998) 'Design and optimisation of a lightweight refrigerated semitrailer', International Journal of Heavy Vehicle Systems, Vol. 5, No. 1, pp.45-68.

Larrodé, E., Miravete, A. and Fernandez, F.J. (1995) 'A new concept of a bus structure made of composite materials by using continuous transversal frames', Composite Structures, Vol. 32, Great Britain.

Lees, W.A. (1984) Adhesives in Engineering Design, London: Springer.

Matthews, F.L. (1987) Joining Fibre-Reinforced Plastics, London: Elsevier Applied Science.

Montgomery, D.C. (1996) Design and Analysis of Experiments, 4th edition, John Wiley and Sons, QA279.M66, Ch. 14.

Otto, K. and Wood, K. (2001) Product Design - Techniques in Reverse Engineering and New Product Development, New Jersey: Prentice-Hall.

Schellens, J. and Peijs, A.A.J.M. (1999) 'Design of a multi-functional semitrailer using structural sandwich panels', Twelfth International Conference on Composite Materials, Paper 1150; Paris, France: On CD-Rom.

Shenoi, R.A. and Wellicome, J.F. (1993) Composite Materials in Maritime Structures, Cambridge: Cambridge University Press.

Vernadat, F.B. (1996) Enterprise Modeling and Integration, Chapman \& Hall. 